American Journal of Agricultural and Biological Sciences 5 (3): 247-255, 2010

ISSN 1557-4989

(C) 2010 Science Publications

\title{
Effect of Plowing Depth of Tillage and Forward Speed on the Performance of a Medium Size Chisel Plow Operating in a Sandy Soil
}

\author{
S.A. Al-Suhaibani and A.E. Ghaly \\ Department of Agricultural Engineering, College of Food Science and Agriculture, \\ King Saud University, P.O. Box 2460, Riyadh 11451 Kingdom of Saudi Arabia
}

\begin{abstract}
Problem statement: Tillage is a process of creating a desirable soil condition for seed germination and growth. The tillage of soil is considered to be one of the biggest farm operations as the tillage operation requires the most energy on the farm. Chisel plow is widely used by farmers as a primary tillage tool. Performance data for chisel plow operation is essential in order to reduce the cost of tillage operation. Approach: Field experiments were conducted using a fully instrumented MS 3090 tractor to measure the draft of a heavy duty chisel plow in a sandy soil over wide ranges of plowing depths and forward speeds. The data were measured and recorded using an instrumentation system and data logger. Results: The effects of plowing depth and forward speeds on draft, unit draft, vertical specific draft, horizontal specific draft and coefficient of pull were evaluated. The results indicated that increasing the plowing depth and/or the forward speed increased the draft, unit draft and vertical specific draft. Also, increasing the plowing depth increased the horizontal specific draft and the coefficient of pull, while increasing the forward speed decreased the horizontal specific draft and the coefficient of pull. Conclusion: About $16.6 \%$ of the draft force was directed towards cutting the soil and $83.4 \%$ was consumed in pulverization of soil particles. The values of the vertical specific draft were much higher than those of the horizontal specific draft for all plowing depths and forward speeds. The plowing depth had more pronounced effect on the draft, unit draft, specific draft and coefficient of pull than the forward speed. The optimum forward speed was $1.75 \mathrm{~m} \mathrm{sec}^{-1}$. The recommended plowing depth should be based on the type of crop (depth of the root system).
\end{abstract}

Key words: Tillage, draft, unit draft, specific draft, coefficient of pull, sandy soil, instrumentation, chisel plow

\section{INTRODUCTION}

The tillage of soil is considered to be one of the biggest farm operations (Finner and Straub, 1985). Gill and Vanden Berg (1968) defined tillage as a process aimed at creating a desired final soil condition for seeds from some undesirable initial soil condition through manipulation of soil with the purpose of increasing crop yield. Several tillage implements are used by farmers to prepare seedbed. However, the selection of tillage implements for seedbed preparation and weed control depends on soil type and condition, type of crop, previous soil treatments, crop residues and weed type (Upadhyaya et al., 2009). One of the tillage implements widely used by farmers is the chisel plow which is considered to be a primary tillage implement because it is mainly used for the initial soil working operations. Chisel plows function most effectively when the soil is dry and firm (Srivastava et al., 1993).
The ability of tillage implements to maintain surface residue coverage is largely dependent on the main active component of implement. Raper (2002) compared two categories of tillage implements to determine their ability to maintain grain sorghum surface residue coverage when operating at two different tillage depths for fall and spring tillage. Chisel-type implements were found to bury substantially less crop residue than disk-type implements. Disk-type implements were found to bury increased amounts of crop residue when operating at deeper tillage depths.

The tillage operation requires the most energy and power spent on farms. Therefore, draft and power requirements are important in order to determine the size of the tractor that could be used for a specific implement. The draft required for a given implement will also be affected by the soil conditions and the geometry of the tillage implement (Taniguchi et al., 1999; Naderloo et al., 2009; Olatunji et al., 2009).

Corresponding Author: S.A. Al-Suhaibani, Department of Agricultural Engineering, College of Food Science and Agriculture, King Saud University, P.O. Box 2460, Riyadh 11451 Kingdom of Saudi Arabia 
The effects of soil conditions, tillage depth and forward speed on soil translocation by chisel plow were studied by Van Muysen et al. (2000). The specific draft (force per cross sectional area of worked soil), energy use for moldboard plow, chisel plow and disc harrow at different soil conditions were investigated by Arvidsson et al. (2004). They found that the specific draft was generally the highest for the chisel plow and the lowest for the moldboard plow and the disc harrow and referred that to the differences in implement geometry and mode of soil break-up.

Several models were developed to predict draft for tillage tools based on soil condition, soil properties and implement width (Sahu and Raheman, 2006). Owen (1989) studied the force-depth relationship of a chisel plow tine with three different wing types in a compacted clay loam soil and found the vertical force on the tine to increase linearly with the operating depth while the horizontal force, moment and total force to increase quadratically with operating depth. He also noticed that the wing width had a significant effect on the vertical force and no interaction existed between the wing width and the depth. The relationship between depth of cut and the increase in the weight of disc plow and the draft was investigated by Olatunji et al. (2004). The model derived from the field work showed that the draft for disc plow increase with speed and soil moisture content and the depth of cut varied with changes in the weight of the implement. Mamman and Qui (2005) studied the draft performance of a chisel plow model using a soil bin. The design parameters considered were: nose angle, slide angle, depth and speed. The draft increased with increases in tillage depth and the levels of nose and slide angles and the cutting edge height.

Brown et al. (1989) stated that manufacturers of tillage implements tend to overdesign their products due to a lack of the proper design and analysis of tools and the technical expertise required to optimize the strength of an implement. Gill and Vanden Berg (1968) stated that the efficiency and economy of the tillage operation could be evaluated from the mechanics of tillage tools/soil interaction which would provide a method by which the performance of the tillage implements could be predicted and controlled by the design of a tillage tool or by the use of a sequence of tillage tools. In studying the strength and forces for the chisel plow, Brown et al. (1989) evaluated the stress on the chisel plow using the finite element analysis and reduced the weight by $23 \%$ without causing excessive stress on the plow.

The main objectives of this study was to evaluate the performance of a medium size (weight $=380 \mathrm{~kg}$,

width $=190 \mathrm{~cm}$ ) chisel plow with three rows of fully curved thin $(5 \mathrm{~cm})$ shanks (7) in a sandy soil. The specific objectives were to study the effects of plowing depth and forward speed on: (a) draft, (b) unit draft, (c) specific draft and coefficient of pull.

\section{MATERIALS AND METHODS}

Tractors and instrumentation system: A fully instrumented Massy Ferguson (MF) 3090 tractor (Fig. 1) was used in the study. The specification of the tractor are presented in Table 1. The instrumentation system consisted of: (a) a drawbar dynamometer, to measure drawbar pull (b) two wheel torque transducers, to measure wheel forces (c) a three-point linkageimplement force and depth transducer, to measure the three-point linkage forces and depth, (d) other transducers, to monitor ground speed, fluid temperatures (engine oil, transmission oil, front axle oil, engine coolant and engine fuel), Power Take Off (PTO) torque, right and left position of front wheel steering and angular position and indication of the lifting position of the three-point linkage, (e) a data logger, to monitor and record data from various parameters and (f) a computer, for processing and analyzing data (AlSuhaibani et al., 1994).

The draft was measured using a drawbar dynamometer (Fig. 2) consisting of two load sensing clevis bolts and the force exerted by the plow was measured by a strain gauge bridge within the clevis bolts.

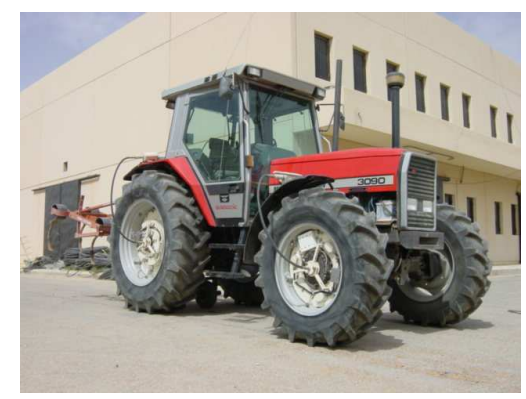

Fig. 1: The fully instrumented tractor

Table 1: Tractor specifications

\begin{tabular}{ll}
\hline Parameter & Value \\
\hline Power & $75 \mathrm{~kW}$ \\
Weight & $47.35 \mathrm{kN}$ \\
Weight on front wheels & $18.50 \mathrm{kN}$ \\
Weight on rear wheels & $28.85 \mathrm{kN}$ \\
Distance between front and rear wheels & $269.90 \mathrm{~cm}$ \\
Distance between front wheels & $187.00 \mathrm{~cm}$ \\
Distance between rear wheels & $163.00 \mathrm{~cm}$ \\
Front wheels size & $31.60 \mathrm{R} 28$ \\
Rear wheels size & $18.40 \mathrm{R} 38$ \\
Height of drawbar & $58.30 \mathrm{~cm}$ \\
Height of center of gravity & $174.00 \mathrm{~cm}$ \\
\hline
\end{tabular}




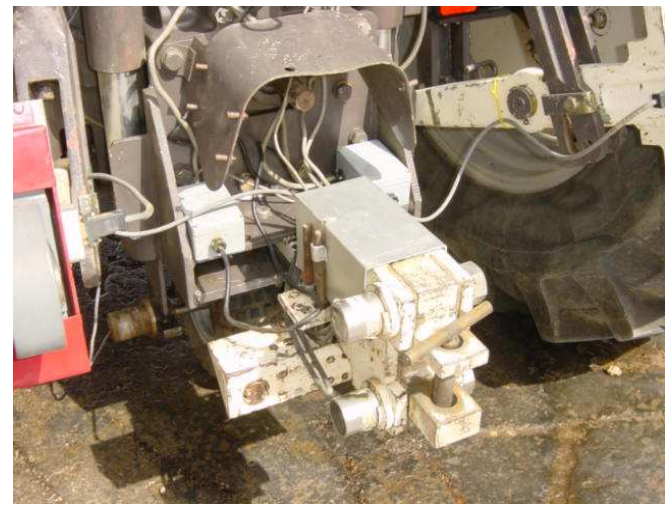

Fig. 2: The draw bar dynamometer used for measuring draft

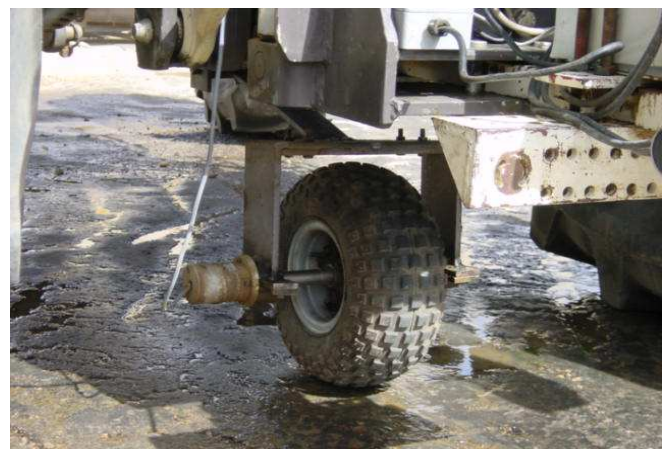

Fig. 3: The fifth wheel used for measuring the forward speed

The tractor ground speed was measured using a fifth wheel attached to a suitable position underneath the tractor as shown in Fig. 3. An RS shaft encoder (360 pulses/revolution) was mounted on the fifth wheel and used to measure the distance traveled and hence the actual ground speed.

The depth was measured using the three point linkage-implement force and depth transducer (Fig. 4) which was developed specifically for use with mounted implement of categories II (40-100 hp) and III (80-225 hp) as specified by the ASAE Standards (1985).

A data logger mounted on a platform to the left of the tractor operator was used to scan and record the output signals from the transducers. The strain gauge transducers in the instrumentation system were connected to the data logger through amplifier boxes, which also provided a regulated power supply to give excitation to the transducer. The activity unit was used to provide excitation to both the data logger and transducers with input supply from the tractor battery $(12 \mathrm{~V})$. It was, also, used to indicate the activity performed during field tests.

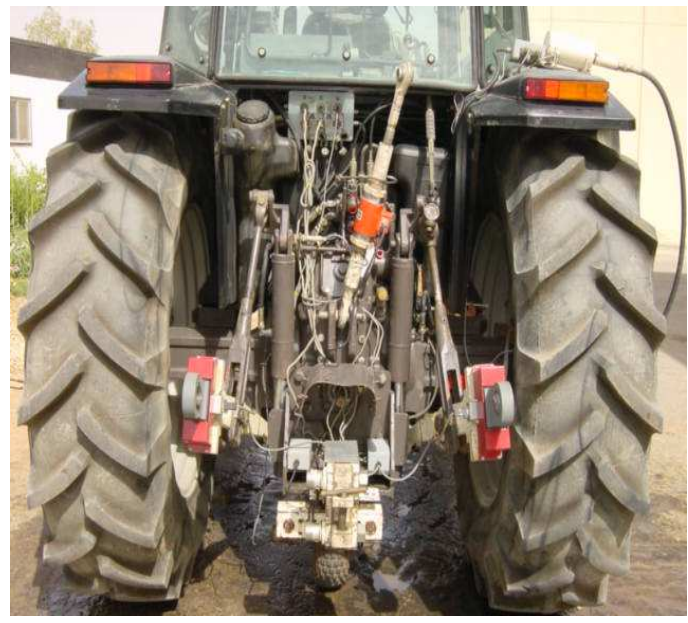

Fig. 4: The system used for measuring forces and determination of tillage depth

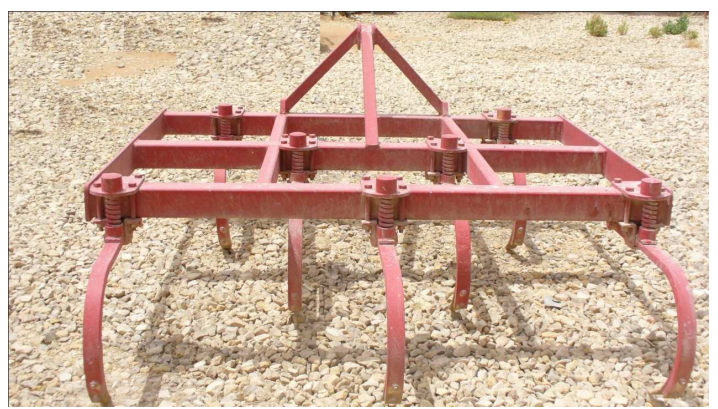

Fig. 5: A medium size chisel plow

Chisel plow: A medium size (Fig. 5) Massy Ferguson (Denmark) chisel plow (model MF 38, serial No. L4078) was used in the study. The plow weighed 380 $\mathrm{Kg}(3.73 \mathrm{kN})$ and had a width of $190 \mathrm{~cm}$. It had 7 shanks distributed in 3 rows. The specifications of the plow are shown in Table 2.

Field experiments: Experiments were conducted using the fully instrumented MF 3090 tractor to measure the draft requirement of a medium size chisel plow in a sandy loam soil over wide ranges of speeds and depths at the Agricultural Research and Experimental Farm of the King Saud University in Dirab. Four speeds and three depths were tested as shown in Table 3. This resulted in 12 treatment combinations. Ten measurements were taken for each treatment combinations at $5 \mathrm{~min}$ intervals. The data logger monitored and recorded the data for depth, speed and draft during the field experiment. The laptop displayed the values of the measured parameters and analyzed the data. 
Am. J. Agri. \& Biol. Sci., 5 (3): 247-255, 2010

Table 2: Chisel plow specifications

\begin{tabular}{ll}
\hline Parameter & Volume \\
\hline Type of plow & Heavy duty \\
Model & $1-1$ (Serial No. 603) \\
Manufacture & IH Company England \\
Total weight & $380 \mathrm{Kg}(3.73 \mathrm{kN})$ \\
Total width of tillage & $210 \mathrm{~cm}$ \\
Number of shanks & 7 \\
Width of shank & $5 \mathrm{~cm}$ \\
Thickness of shank & $2.5 \mathrm{~cm}$ \\
Shank stem angle & $50^{\circ}$ \\
Number of rows & 3 \\
Number of shanks in first row & 2 \\
Distance between shanks in first row & $120 \mathrm{~cm}$ \\
Number of shanks in second row & 2 \\
Distance between shanks in second row & $60 \mathrm{~cm}$ \\
Number of shanks in third row & 3 \\
Distance between shanks in third row & $85 \mathrm{~cm}$ \\
Width of chisel tool & $5 \mathrm{~cm}$ \\
\hline
\end{tabular}

Table 3: Experimental parameters

\begin{tabular}{ll}
\hline Parameter & Values \\
\hline Depth $(\mathrm{mm})$ & $115,160,230$ \\
Speed $\left(\mathrm{m} \mathrm{sec}^{-1}\right)$ & $0.75,1.20,1.75,2.30$ \\
\hline
\end{tabular}

\section{RESULTS}

Figure 6 shows the distribution of shanks on plow frame while Fig. 7 shows the distance between the paths of shanks and the width of worked soil (plowed strip). The width of the plow was $190 \mathrm{~cm}$ and the total width of plowed strip was $210 \mathrm{~cm}$. The total width of cut $(35 \mathrm{~cm})$ was calculated by multiplying the width of shank $(5 \mathrm{~cm})$ by the number of shanks (7). The remaining part of the width of plowed strip $(175 \mathrm{~cm})$ was considered to be the width of pulverization. Accordingly, the plow shanks were able to cut $16.6 \%$ of the total plowed width and the movement of the soil (pulverization) resulted in the breakage of soil particles and preparation of the seedbed.

Table 4 shows the measured draft force $(\mathrm{kN})$ and the calculated unit draft $\left(\mathrm{kN} \mathrm{m}^{-1}\right)$ at various plowing depths and forward speeds. The unit draft is defined in this study as the draft per unit width of the worked soil (width of plowed strip).

Table 5 shows the calculated vertical specific draft $\left(\mathrm{kN} \mathrm{m}^{-2}\right)$ which is defined in this study as the draft per project unit area of vertical cut (vertical cross sectional area of worked soil). The cross sectional area of the worked soil was calculated by multiplying the plowing depth by the width of plowed strip. The portions of the vertical specific draft used for cutting the soil and moving the soil particles (pulverization) were, also, calculated as shown in Table 5.

Table 6 shows the calculated horizontal specific draft. The horizontal specific draft is defined in this study as the draft divided by horizontal plowed area per unit time.
Table 4: Draft and unit draft

\begin{tabular}{llcl}
\hline Depth $(\mathrm{mm})$ & $\begin{array}{l}\text { Speed } \\
\left(\mathrm{m} \mathrm{sec}^{-1}\right)\end{array}$ & Draft $(\mathrm{kN})$ & $\begin{array}{l}\text { Unit draft } \\
\left(\mathrm{kN} \mathrm{m}^{-1}\right)\end{array}$ \\
\hline 115 & 0.75 & $3.14(0.52)$ & 1.50 \\
& 1.20 & $3.76(0.14)$ & 1.79 \\
& 1.75 & $4.11(0.24)$ & 1.96 \\
160 & 2.30 & $4.59(0.25)$ & 2.19 \\
& 0.75 & $5.54(0.38)$ & 2.64 \\
& 1.20 & $6.56(0.38)$ & 3.12 \\
& 1.75 & $7.41(0.14)$ & 3.53 \\
230 & 2.30 & $8.01(0.68)$ & 3.81 \\
& 0.75 & $8.33(0.62)$ & 3.97 \\
& 1.20 & $9.60(0.84)$ & 4.57 \\
& 1.75 & $10.58(0.10)$ & 5.04 \\
& 2.30 & $11.92(1.92)$ & 5.68 \\
\hline
\end{tabular}

( ) The values represent standard deviation; Plow width $=190 \mathrm{~cm}$; Width of plowed strip $=210 \mathrm{~cm}$; Unit draft $=$ Draft $/$ width of plowed strip

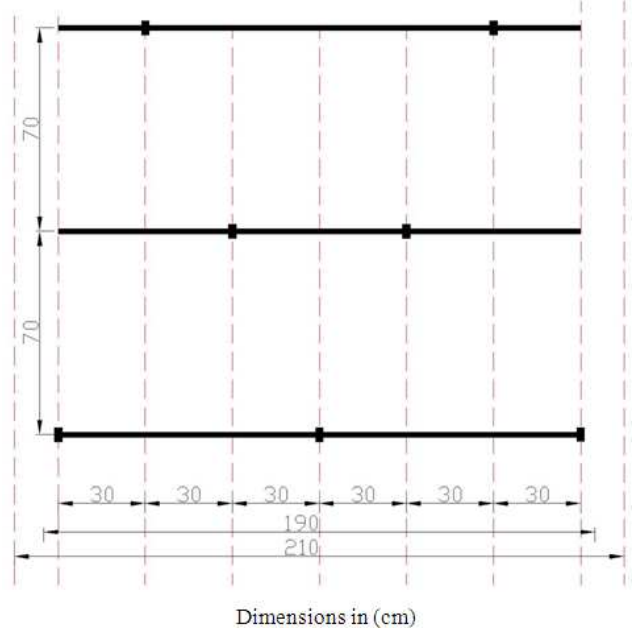

Fig. 6: Distribution of shanks on the plow frame (Plow with $=190 \mathrm{~cm}$; with of tillage $=210 \mathrm{~cm}$; distance between the paths of shanks $=30 \mathrm{~cm}$ )

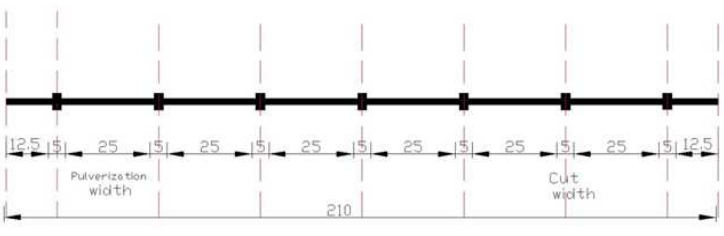

Dimensions in $(\mathrm{cm})$

Fig. 7: Distance between the paths of shanks (total width of tillage $=210 \mathrm{~cm}$; Number of shanks $=$ 7 ; width of chisel tool $=5 \mathrm{~cm}$; total width of cut $=35 \mathrm{~cm} ; \%$ of cut $=16.6 \%$; Width of pulverization $=175 \mathrm{~cm}$; percentage of pulverization $=83.4 \%$ )

The horizontal plowed area per unit time (sec) was calculated by multiplying the forward speed by the width of plowed strip. The results of the vertical specific draft are shown in Table 6. 
Table 7 shows the total weight of the plow and the worked soil (cut/moved) by the plow) at various plowing depths and forward speeds. The weight of worked soil was calculated from the volume of soil created by the plowing depth and the forward movement of the plow in a unit time (sec) and the width of plowed strip. The coefficient of pull $\left(\mathrm{kN} \mathrm{kN}^{-1}\right)$ was calculated by dividing the draft by the total weight of plow and the worked soil. The results are, also, presented in Table 7.

Table 5: Vertical specific draft

\begin{tabular}{|c|c|c|c|c|c|}
\hline \multirow[b]{2}{*}{$\begin{array}{l}\text { Depth } \\
(\mathrm{mm})\end{array}$} & \multirow{2}{*}{$\begin{array}{l}\text { Speed } \\
\left.(\mathrm{m} \mathrm{sec})^{-1}\right)\end{array}$} & \multirow{2}{*}{$\begin{array}{l}\text { Draft } \\
(\mathrm{kN})\end{array}$} & \multicolumn{3}{|c|}{ Vertical specific draft $\left(\mathrm{kN} \mathrm{m}^{-2}\right)$} \\
\hline & & & Total & Cutting & Pulverization \\
\hline \multirow[t]{4}{*}{115} & 0.75 & 3.14 & 13.00 & 2.17 & 10.84 \\
\hline & 1.20 & 3.76 & 15.57 & 2.59 & 12.97 \\
\hline & 1.75 & 4.11 & 17.02 & 2.84 & 14.18 \\
\hline & 2.30 & 4.59 & 19.01 & 3.17 & 15.84 \\
\hline \multirow[t]{4}{*}{160} & 0.75 & 5.54 & 16.49 & 2.75 & 13.74 \\
\hline & 1.20 & 6.56 & 19.52 & 3.25 & 16.27 \\
\hline & 1.75 & 7.41 & 22.05 & 3.68 & 18.38 \\
\hline & 2.30 & 8.01 & 23.84 & 3.97 & 19.87 \\
\hline \multirow[t]{4}{*}{230} & 0.75 & 8.33 & 17.25 & 2.87 & 14.37 \\
\hline & 1.20 & 9.60 & 19.88 & 3.31 & 16.56 \\
\hline & 1.75 & 10.58 & 21.90 & 3.65 & 18.25 \\
\hline & 2.30 & 11.92 & 24.68 & 4.11 & 20.57 \\
\hline
\end{tabular}

Vertical tilled area $=$ Depth of tillage $\times$ width of plowed strip; for a depth of $115 \mathrm{~mm}=0.115 \times 2.1=0.2415 \mathrm{~m}^{2}$; for a depth of $160 \mathrm{~mm}=$ $0.160 \times 2.1=0.3360 \mathrm{~m}^{2}$; for a depth of $230 \mathrm{~mm}=0.230 \times 2.1=0.4830$ $\mathrm{m}^{2} ; \%$ Width of plow strip $=16.6 \%$
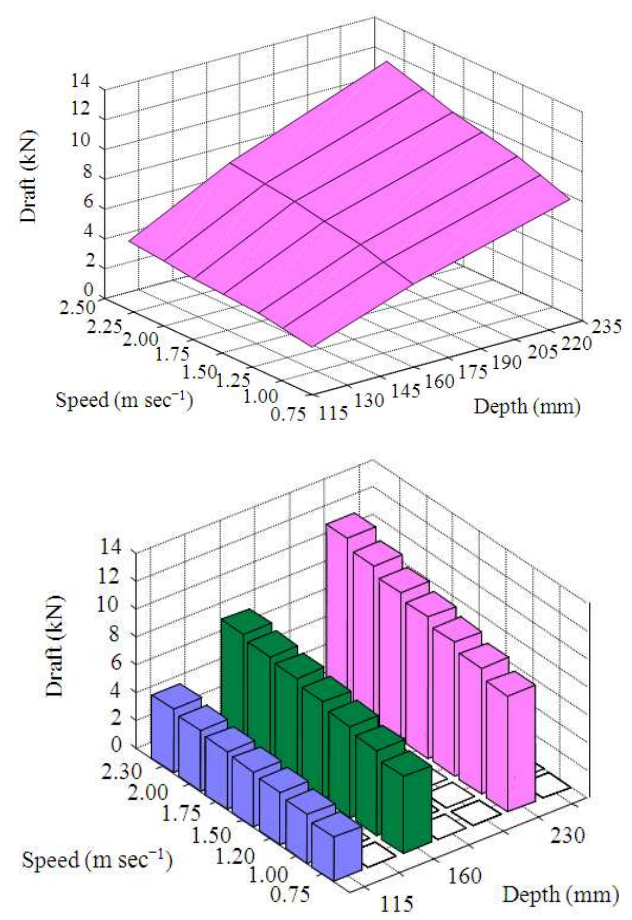

Fig. 8: Effects of plowing depth and forward speed on the measured draft
Figure 8-12 show the effects of plowing depth and forward speed on the draft, unit draft, vertical specific draft, horizontal specific draft and coefficient of pull.

Table 6: Horizontal specific draft

\begin{tabular}{llllll}
\hline $\begin{array}{l}\text { Depth } \\
(\mathrm{mm})\end{array}$ & $\begin{array}{l}\text { Speed } \\
\left(\mathrm{m} \mathrm{sec}^{-1}\right)\end{array}$ & $\begin{array}{l}\text { Draft } \\
(\mathrm{kN})\end{array}$ & $\begin{array}{l}\text { Horizontal specific draft }\left(\mathrm{kN} \mathrm{m}^{-2}\right) \\
\text { Total }\end{array}$ & Cutting & Pulverization \\
\hline 115 & 0.75 & 3.14 & 1.99 & 0.32 & 1.67 \\
& 1.2 & 3.76 & 1.49 & 0.24 & 1.25 \\
& 1.75 & 4.11 & 1.12 & 0.19 & 0.93 \\
& 2.3 & 4.59 & 0.95 & 0.16 & 0.79 \\
160 & 0.75 & 5.54 & 3.52 & 0.58 & 2.94 \\
& 1.2 & 6.56 & 2.6 & 0.43 & 2.17 \\
& 1.75 & 7.41 & 2.02 & 0.33 & 1.69 \\
& 2.3 & 8.01 & 1.65 & 0.28 & 1.37 \\
& 0.75 & 8.33 & 5.29 & 0.88 & 4.41 \\
& 1.2 & 9.6 & 3.81 & 0.63 & 3.18 \\
& 1.75 & 10.58 & 2.88 & 0.48 & 2.4 \\
& 2.3 & 11.92 & 2.47 & 0.41 & 2.06 \\
\hline
\end{tabular}

Horizontal tilled area $=$ Width of tillage $\times$ forward speed; Width of plowed strip $=210 \mathrm{~cm} ; \%$ Width of cut $=16.6 \%$
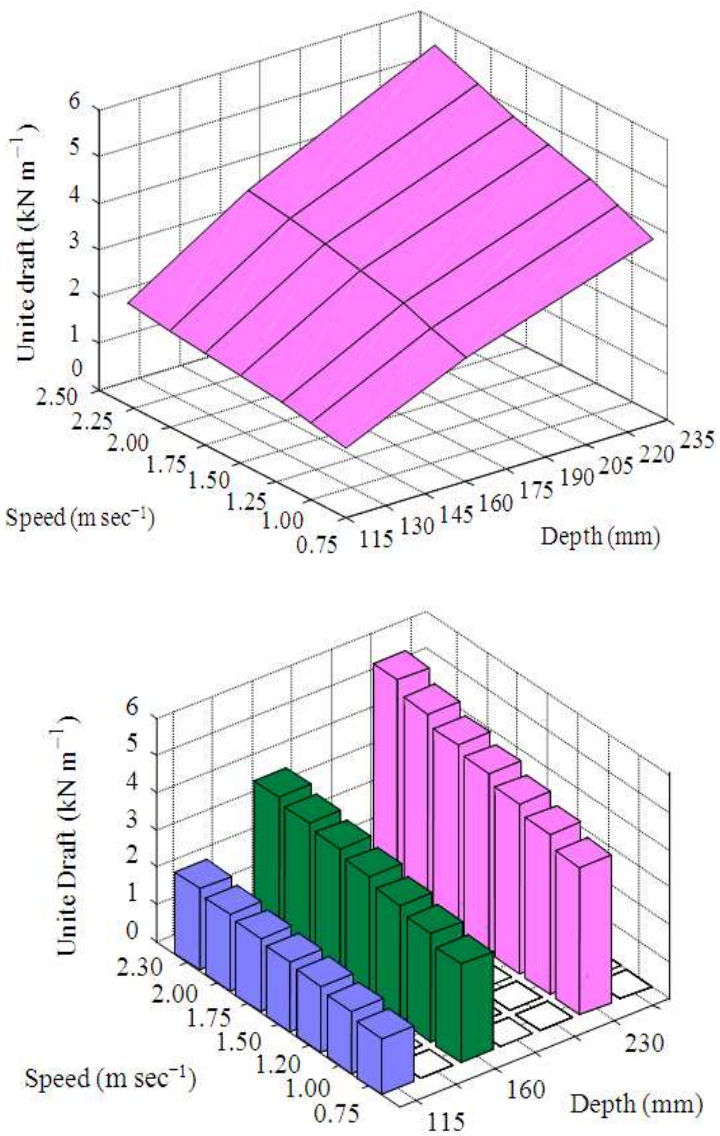

Fig. 9: Effects of plowing depth and forward speed on the unit draft 
Am. J. Agri. \& Biol. Sci., 5 (3): 247-255, 2010

Table 7: Coefficient of pull

\begin{tabular}{llllll}
\hline Depth $(\mathrm{mm})$ & Speed $\left(\mathrm{m} \mathrm{sec}^{-1}\right)$ & Draft $(\mathrm{kN})$ & $\begin{array}{l}\text { Volume } \\
\text { of worked Soil }\left(\mathrm{m}^{3}\right)\end{array}$ & $\begin{array}{l}\text { Weigh of plow } \\
\text { and worked soil }(\mathrm{kN})\end{array}$ & $\begin{array}{l}\text { Coefficient } \\
\text { of pull }\left(\mathrm{kN} \mathrm{kN} \mathrm{kN}^{-1}\right)\end{array}$ \\
\hline 115 & 0.75 & 3.14 & 0.18 & 6.13 & 0.51 \\
& 1.20 & 3.76 & 0.29 & 7.57 & 0.50 \\
& 1.75 & 4.11 & 0.42 & 9.33 & 0.44 \\
160 & 2.30 & 4.59 & 0.56 & 7.09 & 0.41 \\
& 0.75 & 5.54 & 0.25 & 9.07 & 0.78 \\
& 1.20 & 6.56 & 0.40 & 11.52 & 0.72 \\
230 & 1.71 & 0.59 & 13.96 & 0.64 \\
& 2.30 & 8.01 & 0.77 & 8.53 & 0.57 \\
& 0.75 & 9.60 & 0.36 & 11.41 & 0.98 \\
& 1.20 & 10.58 & 0.58 & 14.92 & 0.84 \\
\\
1.75 & 11.92 & 1.11 & 18.44 & 0.71 \\
\end{tabular}

Plow weight $=380 \mathrm{~kg}=3.73 \mathrm{kN}$; Volume of worked soil $=$ Plowed depth $\times$ width of plowed strip $\times$ forward speed; Soil density $=1350 \mathrm{~kg} \mathrm{~m}{ }^{-3}=$ $13.24 \mathrm{kN} \mathrm{m}^{-3}$
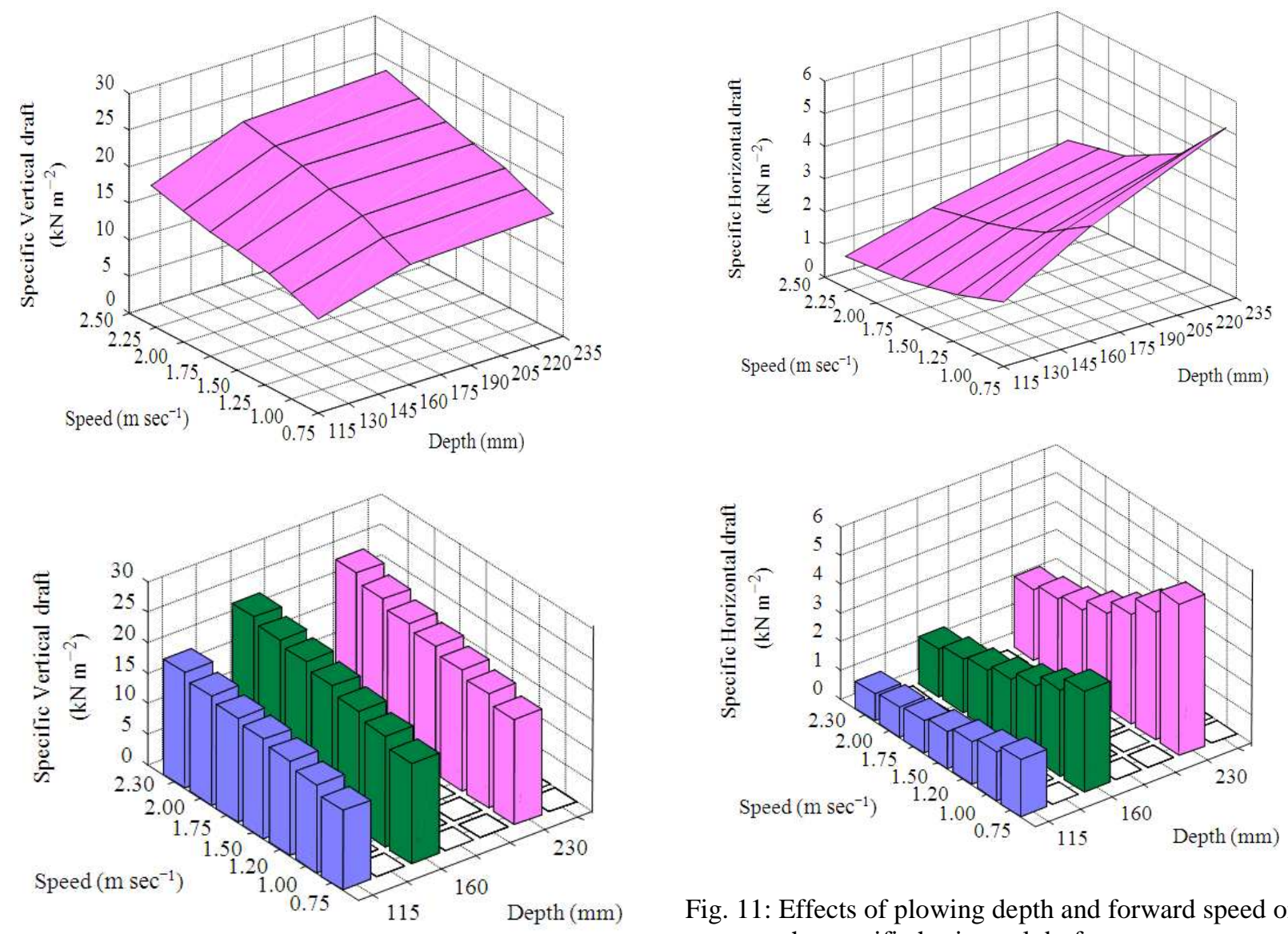

Fig. 11: Effects of plowing depth and forward speed on the specific horizontal draft

Fig. 10: Effects of plowing depth and forward speed on the specific vertical draft

\section{DISCUSSION}

Draft and unit draft: The force required to work (cut and move) the soil varied with both the plowing depth and the forward speed as shown in Table 4 and Fig. 8.

However, the increase in draft with the plowing depth or the forward speed did not appear to be linear as shown in Table 7-9. For all plowing depths, the observed increase in draft when the forward speed was increased from $0.75-1.20 \mathrm{~m} \mathrm{sec}^{-1}$ was higher than the observed increases in draft when the forward speed was increased from $1.20-1.75 \mathrm{~m} \mathrm{sec}^{-1}$ and from $1.75-2.30 \mathrm{~m} \mathrm{sec}^{-1}$. 


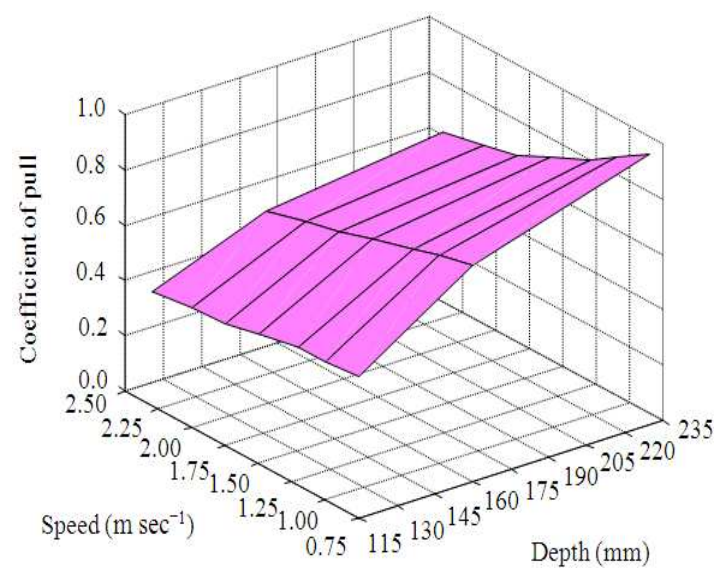

Table 9: The incremental increase in draft with increases in depth at

\begin{tabular}{lll}
\hline $\begin{array}{l}\text { Speed } \\
\left(\mathrm{m} \mathrm{sec}^{-1}\right)\end{array}$ & $\begin{array}{l}\text { Depth intervals } \\
(\mathrm{mm})\end{array}$ & $\begin{array}{l}\text { Increase in } \\
\text { draft }(\mathrm{kN} / \mathrm{m})\end{array}$ \\
\hline 0.75 & $115-160$ & 53.3 \\
& $160-230$ & 39.9 \\
1.2 & $115-160$ & 62.2 \\
& $160-230$ & 57.7 \\
1.75 & $115-160$ & 73.3 \\
& $160-230$ & 45.3 \\
2.3 & $115-160$ & 76.0 \\
& $160-230$ & 55.8 \\
\hline
\end{tabular}

Table 10: Length of roots of common agricultural crops

\begin{tabular}{ll}
\hline Crop & Root length $(\mathrm{mm})$ \\
\hline Egg plant & $50-60$ \\
Clover & $40-50$ \\
Corn & $30-40$ \\
Fava beans & $30-40$ \\
Wheat (all cereals) & $30-40$ \\
Cucumber & 40 \\
Beans & 30 \\
Tomatoes & 25 \\
Lutes & 20 \\
\hline
\end{tabular}

The unit draft was defined in this study as the draft divided by the width of worked soil (width of plowed strip). The results followed the same trend as the draft as shown in Table 4 and Fig. 9. It appears, also, that the plowing depth had more effect on the unit draft than the forward speed. Increasing the depth from 115-230 mm (100\%) increased the unit draft by $164.6,158.3,157.1$ and $159.4 \%$ for the forward speeds of $0.75,1.20,1.75$ and $2.30 \mathrm{~m} \mathrm{sec}^{-1}$, respectively. On the other hand, increasing the forward speed from $0.75-2.30 \mathrm{~m}(206.6 \%)$ increased the unit draft by $46.0,44.3$ and $43.1 \%$ for the plowing depths of 115,160 and $230 \mathrm{~mm}$, respectively. On the average, doubling the plowing depth increased the unit draft by about $159 \%$ while doubling the forward speed increased the unit draft by $21.5 \%$.

Mamman and Qui (2005) studied the performance of a chisel plow and found the speed and tillage depth to have more influence on the draft than the plow design. Sahu and Raheman (2006) found that the effect of speed on the draft was less than that of the depth. Owen (1989) found the vertical force to increase linearly with the plowing depth while the horizontal force to increase quadratically with the plowing depth.

Shallow seed placement (less than $25 \mathrm{~mm}$ ) is

However, the increase in the draft observed when the forward speed was increased from $1.20-1.75 \mathrm{~m} \mathrm{sec}^{-1}$ was lower than the increase in the draft observed when the forward speed was increased from $1.75-2.30 \mathrm{~m} \mathrm{sec}^{-1}$. This may indicate that the forward speed of $1.75 \mathrm{~m} \mathrm{sec}^{-1}$ is the optimum speed. It was, also, observed that the increase in draft when the depth was increased from 115$160 \mathrm{~mm}$ was higher than the increase in the draft when the depth was increased from 160-230 mm. recommended for most crops that are directly seeded (Collins and Fowler, 1996). However, the depth of the crop roots will be a deterministic factor of plowing depth, while the availability of time and implement width will determine the speed required to finish the work on time (Mustafa and Turgut, 2007). The results obtained from this study indicated that the depth has more effect on the draft than the forward speed. 
Therefore, the depth of plowing should be determined based on the root length shown in Table 10. Increasing the forward speed will improve the quality of the seedbed and will not increase the draft proportionally.

Specific draft: The vertical specific draft is defined in this study as the draft per worked vertical cross sectional area. The results presented in Table 5 and Fig. 10 shows that increasing the plowing depth and/or the forward speed increased the vertical specific draft. Increasing the plowing depth from 115-230 mm (100\%) increased the vertical specific draft by $32.7,27.7,28.7$ and $29.8 \%$ for the speeds of $0.75,1.20,1.75$ and $2.30 \mathrm{~m} / \mathrm{s}$, respectively. On the other hand, increasing the forward speed from $0.75-2.30 \mathrm{~m} \mathrm{sec}^{-1}(206.6 \%)$ increased the vertical specific draft by $46.2,43.4$ and $43.1 \%$ for the plowing depths of 115, 160 and $230 \mathrm{~mm}$, respectively. On the average, doubling the plowing depth increased the vertical specific draft by $44.2 \%$ while doubling the forward speed increased the specific draft by $14.4 \%$.

The horizontal specific draft is defined in this study as the draft per worked horizontal area per unit time. The results are presented in Table 6 and Fig. 11 show that increasing the plowing depths of the forward speed increased the horizontal specific draft. Increasing the plowing depth from 115-230 $\mathrm{mm}(100 \%)$ increased the horizontal specific draft by 165.8, 155.7, 157.1 and $166.0 \%$ for the forward speed of $0.75,1.20,1.75$ and $2.30 \mathrm{~m} \mathrm{sec}^{-1}$, respectively. On the other hand, increasing the forward speed from $0.75-2.30 \mathrm{~m} \mathrm{sec}^{-1}$ (206.6\%) reduced the horizontal specific draft by 52.3, 53.1 and $53.3 \%$ for the plowing depths of 115,160 and $230 \mathrm{~mm}$, respectively. On the average, doubling the plowing depth increased the horizontal specific draft by $161.15 \%$, while doubling the forward speed reduced the horizontal specific draft by $25.6 \%$.

It must be noted that the vertical specific draft has much higher values than those of the horizontal specific draft, indicating that the depth of plowing has significantly more effect on the specific draft than the forward speed. Increasing the depth increased both the vertical specific draft and horizontal specific draft while increasing the forward speed increased the vertical specific draft and reduced the horizontal specific draft. This could have a significant impact on the economical tillage. Van Muysen at al. (2000) stated that the specific draft is affected by the tool geometry.

Coefficient of pull: The coefficient of pull is defined in this study as the draft divided by the total weight of the plow and the worked soil. The weight of the worked soil was determined by multiplying the soil density by the volume of the worked soil. The volume of the worked soil was determined by multiplying the plowed depth by the width of plowed strip by the forward speed. The results presented in Table 7 and Fig. 12 show that increasing the depth of plowing increased the coefficient of pull for all forward speeds. Increasing the plow depth from 115-230 mm (100\%) increased the coefficient of pull by $92.1,68.0,61.3$ and $58.5 \%$ for the forward speeds of $0.75,1.20,1.75$ and $2.30 \mathrm{~m} \mathrm{sec}^{-1}$, respectively. On the other hand, increasing the forward speed from $0.75-2.30 \mathrm{~m} \mathrm{sec}^{-1}$ (206.6\%) reduced the coefficient of pull by 19.6, 26.9 and $33.7 \%$ for the plowing depths of 115,160 and $230 \mathrm{~mm}$, respectively.

\section{CONCLUSION}

The effects of plowing depth and forward speeds on draft, unit draft, vertical draft, horizontal draft and coefficient of pull were evaluated. The results indicated that increasing the plowing depth and/or the forward speed increased the draft, unit draft and vertical specific draft. Also, increasing the plowing depth increased the horizontal specific draft and the coefficient of pull, while increasing the speed decreased the horizontal specific draft and the coefficient of pull.

About $16.6 \%$ of the draft force was directed towards cutting the soil and $83.4 \%$ was consumed in pulverization of soil particles. The values of the vertical specific draft were much higher than those of the horizontal specific draft for all plowing depths and forward speeds. The plowing depth had more pronounced effect on the draft, unit draft, specific draft and coefficient of pull than the forward speed. The optimum forward speed was $1.75 \mathrm{~m} \mathrm{sec}^{-1}$. The recommended plowing depth should be based on the type of crop (depth of the root system).

Shallow seed placement (less than $25 \mathrm{~mm}$ ) is recommended for most crops that are directly seeded. However, the depth of the crop roots to be raised is a deterministic factor of plowing depth, while the availability of time and implement width will determine the speed required to finish the work on time. The results obtained from this study indicated that the depth has more effect on the draft. Therefore, the depth of plowing should be determined based on the root length.

\section{ACKNOWLEDGEMENT}

The study was founded by King Saud University. The assistance provided by Engineers Yousef AlMajhadi, Ibrahim Tabash and Mohamed Sharaf during the field work and data analysis is highly appreciated. 


\section{REFERENCES}

Al-Suhaibani, S.A., A.A. Bedri, A.S. Babeir and J. Kilgour, 1994. Mobile instrumentation package for monitoring tractor performance. King Saud University, Riyadh. Agric. Eng. Res. Bull., 40: 26.

Arvidsson, J., T. Keller and K. Gustafsson, 2004. Specific draught for mouldboard plough, chisel plough and disc harrow at different water contents. Soil Tillage Res., 79: 221-231.

ASAE Standards, 1985. American Society of Agricultural Engineers, Ste. Joseph, Michigan, IL. http://Asae.frymulti.com.standards.asp

Brown, N.H., M.A. Gerein and R.L. Kushwaha, 1989. Cultivator design modifications using finite element analysis. Applied Eng. Agric., 5: 148-152.

Collins, B.A. and D.B. Fowler, 1996. Effect of soil characteristics, seeding depth, operating speed and opener design on draft force during direct seeding. Soil Tillage Res., 39L 199-211.

Finner, M.F. and R.J. Straub, 1985. Farm Machinery Fundamentals. American Pub. Co., Madison, WI, USA., pp: 143.

Gill, W.R. and G.E. Vanden Berg, 1968. Soil Dynamics in Tillage and Traction, Agricultural Research Service. USDA, US Government Printing Office, Washington, DC, Design of Tillage Tools, pp: 211-297. http://asae.frymulti.com/abstract.asp?aid=26876\&t=2

Mamman, E. and K.C. Oni, 2005. Draught performance of a range of model chisel furrowers. Agric. Eng. Int. CIGR E J., 3: 1-17. http://www.cigrjournal.org/index.php/Ejounral/arti cle/view/601/595

Mustafa, G.B. and N. Turgut, 2007. Effect of tillage implements and operating speeds on soil physical properties and wheat emergence. Turk. J. Agric. For., 31: 399-412.

Naderloo, L., R. Alimadani, A. Akram, P. Javadikia and H.Z. Khanghah, 2009. Tillage depth and forward speed effects on draft of three primary tillage implements in clay loam soil. J. Food Agric. Environ., 7: 382-385.
Olatunji, O.M., W.I. Burubai and R.M. Davies, 2004. Effect of weight and draught on the performance of disc plough on sandy loam soil. Elect. J. Environ. Agric. Food Chem., 8: 544-556.

Olatunji, O.M., W.I. Burubai and R.M. Davies, 2009. Effect of weight and draught on the performance of disc plough on sandy loam soil. J. Applied Sci. Eng. Technol., 1: 22-26.

Owen, G.T., 1989. Force-depth relationships in a pedogenetically compacted clay loam soil. Applied Eng. Agric., 5: 185-191.

Raper, R.L., 2002. The influence of implement type tillage depth and tillage timing on residue burial. Trans. Am. Soc. Agric. Biol. Eng., 45: 1281-1286.

Sahu, R.K. and H. Raheman, 2006. Draught prediction of agricultural implements using reference tillage tools in sandy clay loam soil. Biosyst. Eng., 94: 275-284.

Srivastava, A.K., C.E. Goering and R.P. Rohrbach, 1993. Engineering Principles of Agricultural Machines. ASAE Textbook, pp: 149-219.

Taniguchi, T., J.T. Makanga, K. Ohtomo, T. Kishimoto, 1999. Draft and soil manipulation by a moldboard plow under different forward speed and body attachments. Trans. Am. Soc. Agric. Biol. Eng., 42: 1517-1521.

Upadhyaya, S.K., P. Andrade-Sanchez, K. Sakai, W.J. Chancellor and R.J. Godwin, 2009. Advances in Soil Dynamics. Vol. 3 Chapter 3, Parts I and II, American Society of Agricultural and Biological Engineers, pp: 273-359.

Van Muysen, W., G. Govers, K. van Oost and A. van Rompaey, 2000. The effect of tillage depth, tillage speed and soil condition on chisel tillage erosivity. J. Soil Water Conserv., 55: 355-364. http://www.jswconline.org/Content/ss/3/355.full.pdf 